\title{
BMJ Open Prevalence and forms of gender discrimination and sexual harassment among medical students and physicians in French-speaking Switzerland:
} a survey

\author{
Iris Najjar (1D , ${ }^{1}$ Jennifer Socquet, ${ }^{2}$ Angele Gayet-Ageron (1D , ${ }^{3}$ Bara Ricou, ${ }^{4,5}$ \\ Julien Le Breton, ${ }^{6}$ Anne Rossel, ${ }^{1}$ Jasmine Abdulcadir, ${ }^{7}$ Cindy Soroken, ${ }^{8}$ \\ Elena Tessitore (D , ${ }^{9}$ Caroline Gerstel, ${ }^{10}$ Julie Halimi, ${ }^{11}$ Giulia Frasca Polara, ${ }^{12}$ \\ Matteo Coen (D) , ${ }^{1,5}$ Eva Niyibizi ${ }^{13}$
}

To cite: Najjar I, Socquet J, Gayet-Ageron A, et al. Prevalence and forms of gender discrimination and sexual harassment among medical students and physicians in French-speaking Switzerland: a survey. BMJ Open 2022;12:e049520. doi:10.1136/ bmjopen-2021-049520

- Prepublication history and additional supplemental material for this paper are available online. To view these files, please visit the journal online (http://dx.doi.org/10.1136/ bmjopen-2021-049520).

IN and JS contributed equally. $\mathrm{MC}$ and EN contributed equally.

Received 28 January 2021 Accepted 02 December 2021

Check for updates

(c) Author(s) (or their employer(s)) 2022. Re-use permitted under CC BY-NC. No commercial re-use. See rights and permissions. Published by BMJ.

For numbered affiliations see end of article.

Correspondence to

Dr Iris Najjar;

iris.najjar@gmail.com

\section{ABSTRACT}

Objectives The aim of this study was to determine the prevalence and forms of gender discrimination and sexual harassment experienced by medical students and physicians in French-speaking part of Switzerland.

Design and setting We conducted an online survey using a questionnaire of 9 multiple-choice and 2 open questions between 24 January 2019 and 24 February 2019. Our target population was medical students and physicians working at hospitals and general practitioners from the French-speaking part of Switzerland. The online survey was sent via social media platforms and direct emails. We compared answers between male-determined and femaledetermined respondents using either $\chi^{2}$ or Fisher's exact tests.

Results Among 1071 responders, a total of 893 were included (625 females, 264 males, 4 non-binary and 1 non-binary and male). 178 were excluded because they did not mention their working place or were working only outside Switzerland. Because of the small number of non-binary participants, they were not contemplated in further statistical analysis. Of 889 participants left, 199 (31.8\%) women and 18 (6.8\%) men reported having personally experienced gender discrimination, in terms of sexism, difficulties in career development and psychological pressure. Among women, senior attendings were the most affected (55.2\%), followed by residents (44.1\%) and junior attendings (41.1\%). Sexual harassment was equally observed among women (19.0\%) and men (16.7\%). Compared with men (47.0\%), women (61.4\%) expressed the need to promote equality and inclusivity in medicine more frequently $(p<0.001)$, as well as the need for support in their professional development (38.7\% women and $23.9 \%$ men; $p<0.001$ ). Conclusions Gender discrimination in medicine in Frenchspeaking Switzerland affects one-third of women, in particular, those working in hospital settings and senior positions.

\section{INTRODUCTION}

Achieving gender equality is the number 5 goal of the United Nations' 17 sustainable development goals to be fulfilled by $2030 .{ }^{1}$
Strengths and limitations of this study

- The study includes students and medical professionals in different working environments (university, public hospital and medical practice).

- The study has a high number of participants.

- The response rate could not be estimated as the total number of persons reached via social media is unknown.

- The study did not take into account race or ethnicity, which can also play a role in discrimination.

The magnitude of the feminist movements like \#MeToo and the emergence of organisations providing legal and professional support for women like TIME'S UP and TIME'S UP Healthcare demonstrate the issue has starkly mobilised civil society; both instances signal, finally, the widespread presence of sexism and sexual harassment in professional environments. ${ }^{2}$ Sexism is commonly defined as a discrimination based on gender and often used as a synonym to gender discrimination. Sexual harassment is defined as 'any unwelcome sexual advance, request for sexual favours or other verbal or physical conduct of a sexual nature, when it interferes with work, is made a condition of employment, or creates an intimidating, hostile or offensive work environment'. ${ }^{3}$ The medical field is no exception to this phenomenon with numerous international studies showing alarming results. ${ }^{4-7}$ In a survey published in the Journal of the American Medical Association in 2016, 66\% of female research clinicians reported having endured gender-related discrimination, and $30 \%$ sexual harassment. ${ }^{4}$ Furthermore, although the female component of frontline 
healthcare workers reaches $70 \%, 75 \%$ of top leadership positions in academia and medical specialties are still held by men. ${ }^{8-12}$ The 2019 LeanIn.Org and McKinsey survey 'Women in the healthcare industry' highlighted the influence of gender and ethnicity in the underrepresentation of women in leadership positions. ${ }^{13}$ Gender pay gaps persist as pointed out by the study 'Gender pay gap in medicine' conducted by the United Kingdom National Health Services in 2019. This study found a gender pay gap of $17 \%$, with a difference of $33 \%$ in general practitioners' practices. ${ }^{10}$ In Switzerland, the 2019 Statistics of the Foederatio Medicorum Helveticorum (Federation of the Swiss physicians) showed that $57.8 \%$ of residents are women, but only $12.8 \%$ of female physicians occupy department chairs positions. ${ }^{14}$ MedFem, an association of physicians working toward more equality and inclusivity in the medical field, conducted the present survey in French-speaking Switzerland. ${ }^{15}$ It is the first survey effort on sexism and sexual harassment in medicine in that country. The objectives of this study were: (1) to determine the prevalence and forms of sexism and gender discrimination endured by medical students and physicians across specialities, (2) to evaluate their needs regarding this issue and (3) to collect their opinion on the improvements needed in the future.

\section{METHODS}

We conducted an online survey in French using Monkey Survey that was available from 24 January 2019 to 24 February 2019. The questionnaire was reviewed by four members of the association MedFem. Following the review, an introduction was added to make the objectives of the survey more clear, to present the association MedFem and to inform about its anonymity. It was pretested among 164 participants, and their answers were second deleted. Following the pretest, a question was added on place of practice. The questionnaire was sent on social media platforms (Facebook, LinkedIn, WhatsApp and Twitter), but direct emails were also sent to medical students of the University of Geneva and University of Lausanne from second to sixth pregaduate years, to physicians working at the University Hospitals of Geneva across different specialities (ambulatory medicine, neurology, visceral surgery, radiology, internal medicine, gynaecology and geriatrics) at the Lausanne university hospital (CHUV), to the hospitals of Neuchâtel and to members of the Delta network in Geneva, a group of general practitioners. ${ }^{16}$ No reminder was send. The choice to include exclusively students and healthcare professionals working in the French-speaking part of Switzerland (Romandy) was dictated by the simplicity to use only French in the survey and to be homogeneous regarding working conditions and cultural aspects linked with the topic. Indeed, wide cultural, professional and linguistic gaps exist between the four language regions (viz, French-speaking, Germanspeaking, Italian-speaking and Romansh-speaking). ${ }^{17}$ The questionnaire was composed of 9 multiple-choice questions (with multiple answer options) and 2 openended questions (questions 9 and 11) and had an estimated fill-out time of $4 \mathrm{~min}$ (online supplemental appendix 1). To note, question 9 permitted participants to express their opinion on improvements needed and on remaining challenges. Question 11 allowed participants to add a general comment. Answers were categorised manually using thematic groups (13 groups for question 9, eg, part-time work, wage equality and career progression; 9 groups for question 11, eg, equality between genders, encouragement and gratitude, no comment).

All variables in the questionnaire were categorical; they were reported by their frequencies and relative percentages by category. We compared various answers to questions between respondents who defined themselves as men and those as women. We performed either $\chi^{2}$ test or the bilateral Fisher's exact t test, when expected frequencies were $\leq 5$, using the software STATA 16 IC (Stata Corp., Texas, USA). A $p$ value of $\leq 0.05$ was considered as statistically significant.

\section{PATIENT AND PUBLIC INVOLVEMENT STATEMENT}

MedFem members were involved from the very beginning and during every stage of the research, that is, brainstorming, conceptualisation, method development and realisation. It is worth noticing that membership to MedFem is open to everyone interested using an online application form. ${ }^{15}$ We will disseminate the results by sharing the published article via the website and Twitter account of MedFem.

\section{RESULTS}

Of the 1071 respondents, 893 were included in our analysis. We excluded 14 respondents who were working outside Switzerland and 164 who did not mention their working place. Participants were either medical students $(41.1 \%)$ or medical doctors from junior to more senior physicians $(58.9 \%)$. The total number of persons reached through our survey is unknown since it was also shared via social media platforms. The response rate among general practitioners in Geneva was 207/439 (47.2\%). The response rate of medical students and physicians working in the above-mentioned hospitals is unknown.

Of the 893 included participants, $625(70.0 \%)$ were female, $264(29.6 \%)$ male and 5 did not identify to a binary gender $(0.6 \%)$ (of these, 1 identified as male and non-binary). The demographic characteristics of participants are summarised in table 1 . Because of their small number, participants who identified as non-binary where not contemplated in further analysis. Medical students were the most numerous to participate with $367 / 893$ $(41.1 \%)$ and participation decreased with seniority. Distribution of the professional position was similar between genders except for the attending position which was occupied by twice as many men than women. The workplace distribution between genders was similar: the majority 
Table 1 Demographic characteristics of participants and distribution according to professional position, workplace and gender

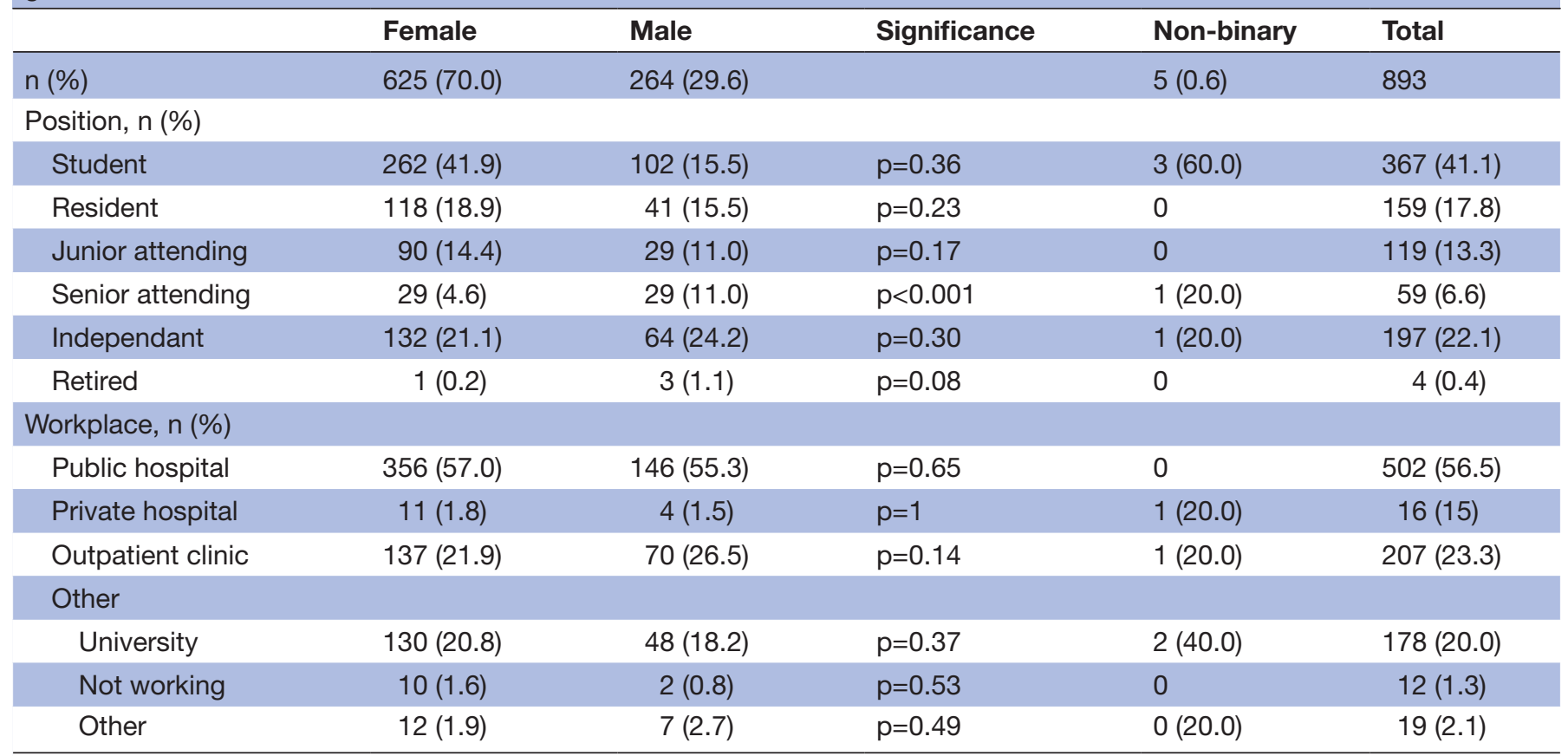

n, number of persons.

worked in public hospitals, followed by outpatient clinics and universities. Most participants had less than 5 years of professional experience. Compared with men, women reported having less professional experience (figure 1).

Among participants, 217/889 (24.4\%) reported that they had suffered acts of discrimination, sexism or gender inequalities. Of these, 199/625 (31.8\%) were women and $18 / 264(6.8 \%)$ were men $(\mathrm{p}<0.001)$ (figure 2$)$. Among women, senior attendings (médecins adjoint·e·s) were the most affected with $16 / 29(55.2 \%)$, followed by

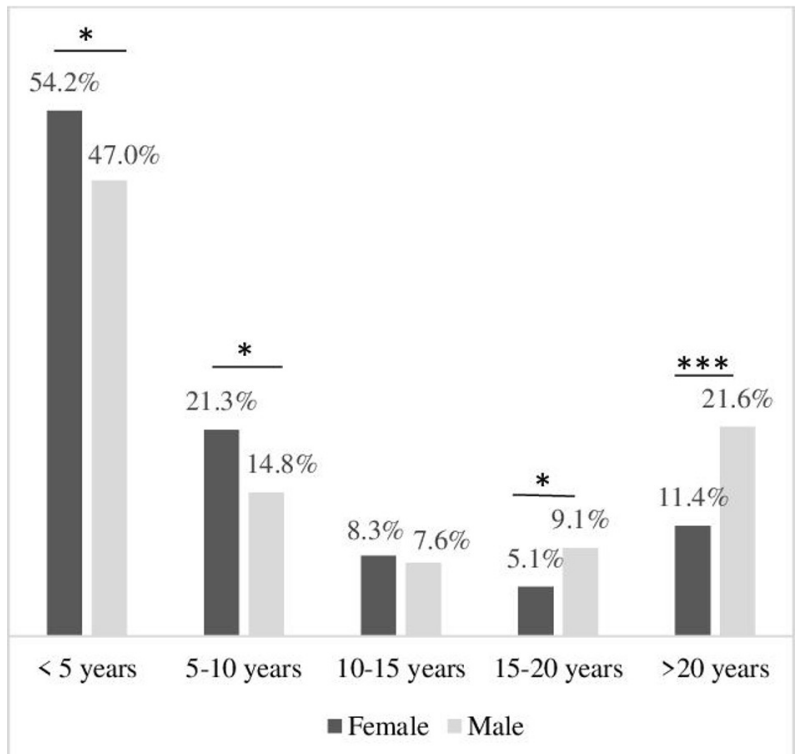

Figure 1 Distribution of participants according to gender and work experience. ${ }^{*} p<0.05 ;{ }^{\star * \star} p<0.001$. residents (médecins internes ou assisent.e.s) with 52/118 $(44.1 \%)$ and junior attendings (chef.fe·s de Clinique) with $37 / 90(41.1 \%)$ (figure 3$)$. The same proportion of women $(166 / 625 ; 26.6 \%)$ and men $(73 / 264 ; 27.6 \%)$ reported having witnessed acts of sexism and discrimination or gender inequality ( $>0.05)$ (not shown in figure). Male residents, junior and senior attendings witnessed acts of discrimination, sexism or gender inequality more frequently compared with their female peers, the difference being statistically significant among residents (figure 4). When the question was raised differently ('In

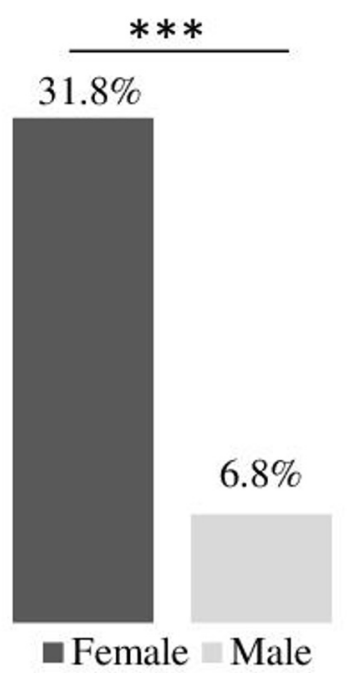

Figure 2 Participants victim of discrimination, sexism or gender inequalities according to gender. ${ }^{\star \star *} p<0.001$. 


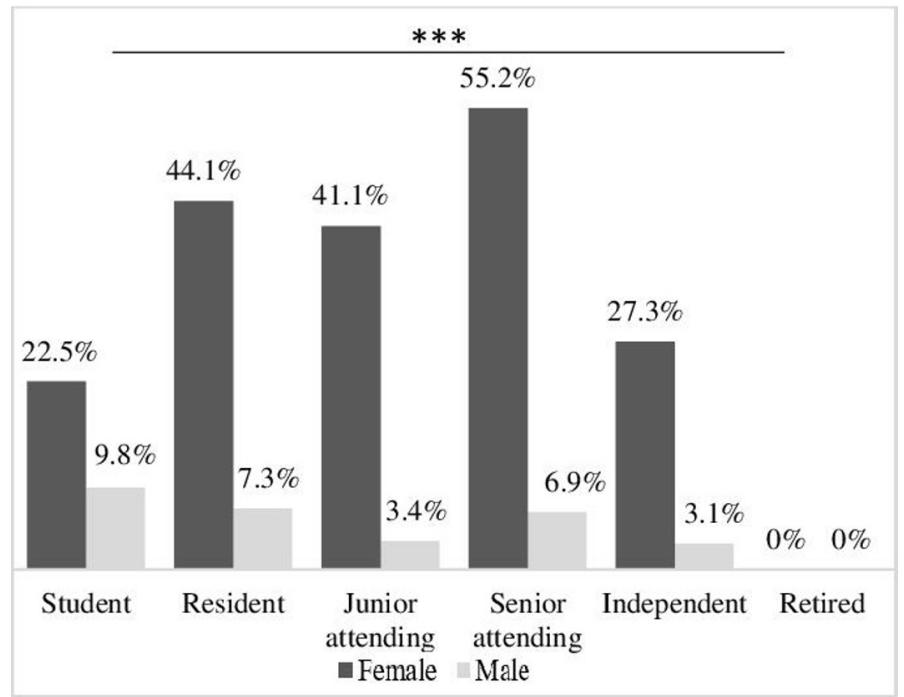

Figure 3 Victims of discrimination, sexism, gender inequality according to professional position and gender. ${ }^{\star \star \star} p<0.001$.

your opinion, what problems have you observed?'), the proportion of total participants that reported having observed acts of sexism increased to $365 / 889(41.1 \%)$, with no statistically significant difference between genders $(\mathrm{p}=0.4)$ (figure 5).

Compared with men, significantly more women reported difficulties in career development $(\mathrm{p}<0.001)$, discrimination in hiring and working conditions $(\mathrm{p}=0.002)$, non-respect of maternity laws $(\mathrm{p}=0.003)$ and difficult access to research opportunities $(\mathrm{p}=0.01)$ as shown in figure 5 . Among participants, 119/625 (19.0\%) women and 44/264 (16.7\%) men had observed sexual harassment $(p>0.05)$. Twice as many men reported having detected no problems $(88 / 625(14.1 \%)$ women and 75/264 (28.4\%) men; $\mathrm{p}=0.004$ ) (figure 5) and not feeling concerned (48/625 (7.7\%) women and 40/264 $(15.1 \%)$ men; $\mathrm{p}<0.001)$ (not shown in figure). On the other hand, a higher proportion of men than of women indicated supporting initiatives to change medical culture (398/625 (63.7\%) women and 188/264 (71.2\%) men; $\mathrm{p}=0.03$ ) (not shown in figure).

Although both women and men perceived the promotion of equality and inclusion in medicine as the most important need, a significant gender difference was observed (figure 6). Women expressed statistically significantly more frequently the need to be supported in their career development $(\mathrm{p}<0.001)$ and to gain knowledge about their rights and have them respected more frequently $(p<0.005)$ (figure 6$)$. Statistically significantly more men reported having no particular need $(p<0.001)$ (figure 6).

Three hundred and fifty nine out of 625 women (57.4\%) and 146/264 men (55.3\%) replied to the open questions. Compared with men, new aspects that were

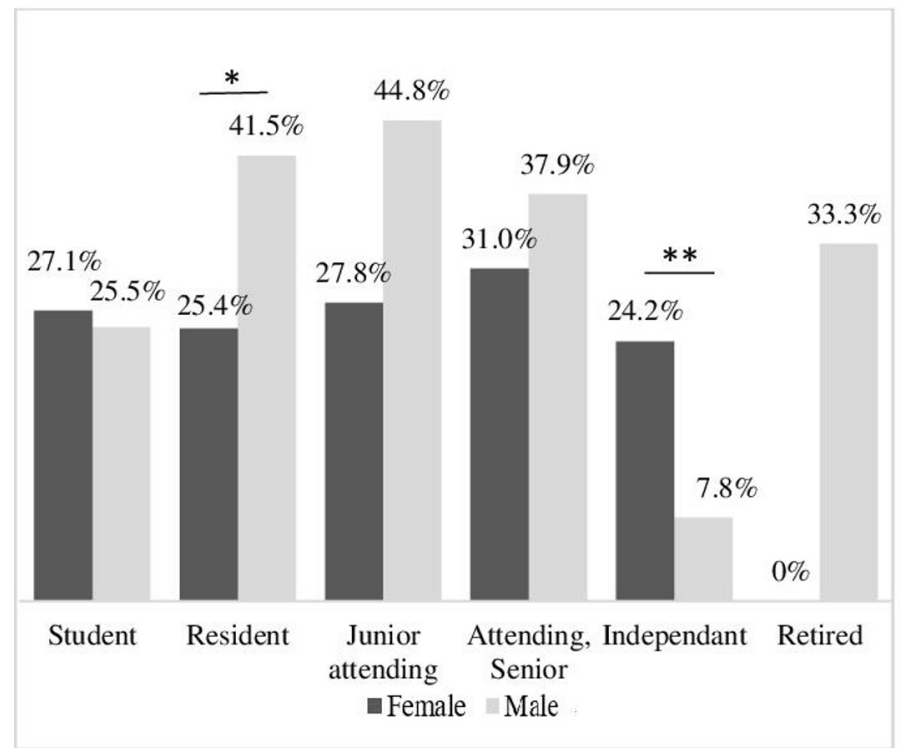

Figure 4 Witnesses of discrimination, sexism and gender inequality according to professional position and gender. ${ }^{*} p<0.05$; ${ }^{* *} \mathrm{p}<0.01$. 


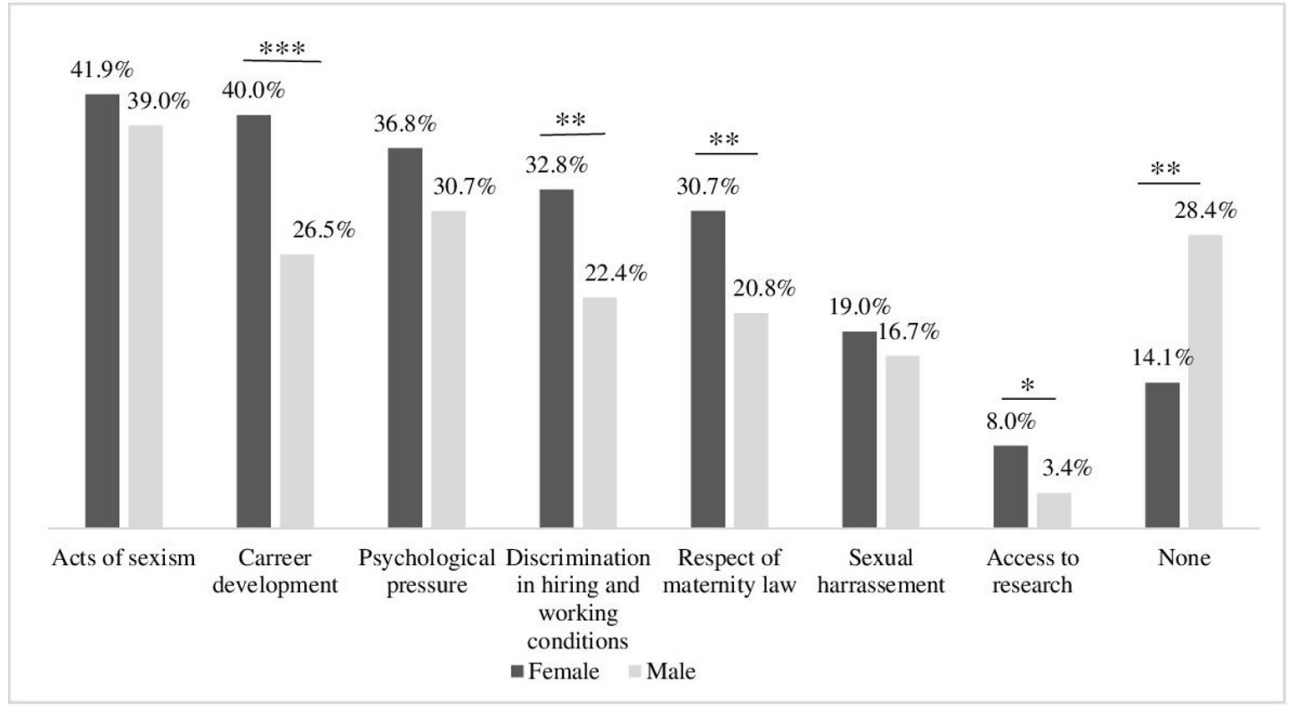

Figure 5 Problems observed by participants according to gender. ${ }^{*} \mathrm{p}<0.05 ;{ }^{* *} \mathrm{p}<0.01 ;{ }^{* * *} \mathrm{p}<0.001$.

more frequently highlighted by women, that had not been referred to in the survey, were the necessity of parttime work $(60 / 359(16.7 \%)$ women and $10 / 146(6.8 \%)$ men; $\mathrm{p}=0.004)$, wage equality $(44 / 359(12.3 \%)$ women and $5 / 146(3.4 \%)$ men; $\mathrm{p}=0.002)$ and equal opportunities in career progression with, among others, appointment of more women in leading positions $(63 / 359(17.5 \%)$ women and 13/146 (8.9\%) men; $\mathrm{p}=0.01)$. Five out of 359 women $(1.4 \%)$-but no men-referred to the notion of 'glass ceiling'. Men highlighted mostly the importance of respect, communication and exchange between genders $(37 / 359$ (10.3\%) women and 24/146 (16.4\%) men; $\mathrm{p}=0.9$ ) and the need to promote equality in a broad sense (55/359 (15.3\%) women and 23/146 (15.8\%) men; $\mathrm{p}=0.9$ ). Women and men reported the need to improve paternal leave laws equally $(27 / 359(7.5 \%)$ women and $10 / 146(6.8 \%)$ men; $\mathrm{p}=0.8)$.

\section{DISCUSSION}

To the best of our knowledge, this study is the first to assess the extent of gender-related discrimination in the medical community of French-speaking Switzerland. Our study shows that discrimination, sexism and gender inequality in medicine affects one-third of women (31.8\%) and a small portion of men $(6.8 \%)$. Interestingly, gender discrimination and sexual harassment were witnessed by women and men equally, thus demonstrating the general awareness of the issue. Recent studies conducted among research clinicians and emergency physicians in the USA, in turn, reported higher rates of gender discrimination than in our study reaching $66.3 \%$ (research clinicians) and $62.7 \%$ (emergency physicians) in women and $9.8 \%$ and $12.5 \%$ in men. ${ }^{4}{ }^{18}$ The overrepresentation of medical students in our study $(40.9 \%)$, reporting less gender discrimination $(22.5 \%$ in female students and

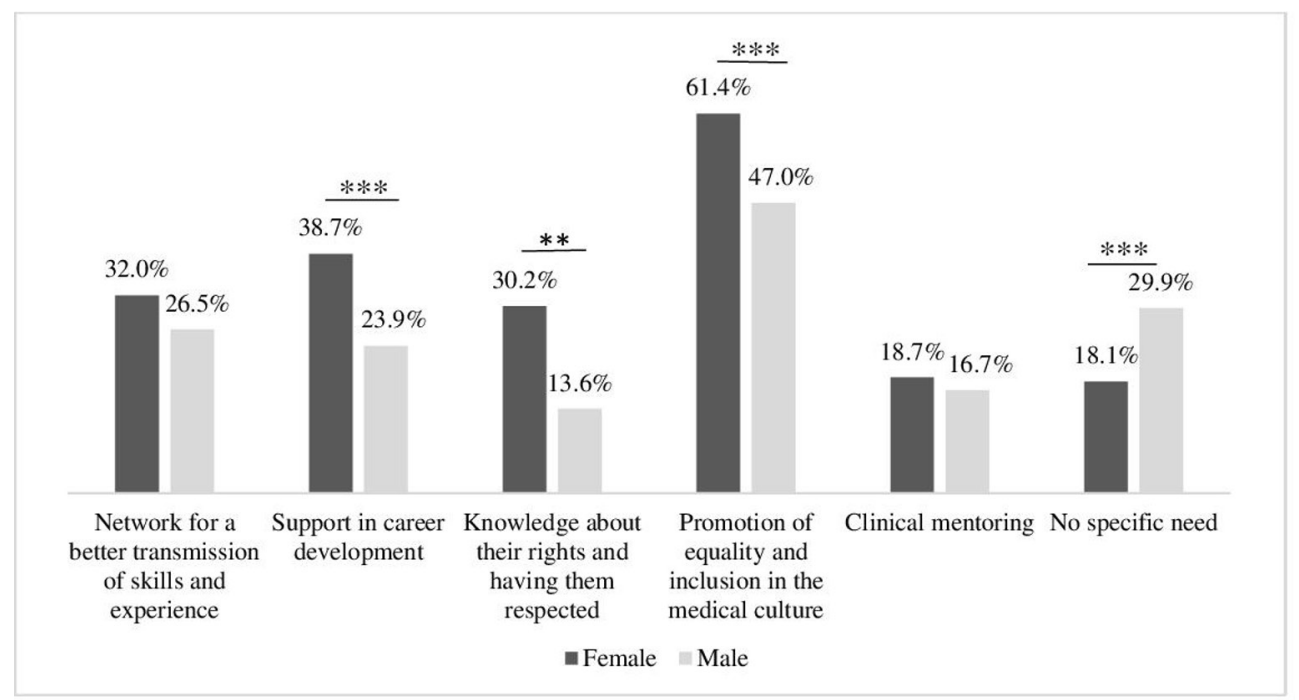

Figure 6 Needs of participants according to gender. ${ }^{*} p<0.05 ;{ }^{* \star} p<0.01 ;{ }^{* \star *} p<0.001$. 
$9.8 \%$ in male students) compared with senior attending physicians $(55.2 \%$ for female responders vs $6.9 \%$ for male responders) could partly explain these differences. Cumulative work experience only partly explains why female senior attendings report the highest incidence of gender discrimination. In fact, women working in an independent medical practice with a seniority comparable to junior or senior attending physicians reported only $27.3 \%$ of gender-related discrimination. These findings suggest that female attending physicians working in hospitals in French-speaking Switzerland are the most affected by gender discrimination and sexism. Addressing this issue is crucial as gender discrimination was shown to have long-lasting consequences on victims' well-being, from decreased self-confidence and burnouts to prompting professional reorientation or a change in medical specialisation. ${ }^{14-17}$

Recent studies carried out in Germany found an alarming rate of physicians $(76.1 \%$ of women and $61.6 \%$ of men) and medical students $(59.8 \%)$ that reported having experienced acts of sexual harassment. ${ }^{19}{ }^{20}$ In the present survey, participants were not asked if they had experienced acts of sexual harassment, but rather if they had witnessed this kind of acts; the reported rates were much lower (19.7\% of women and $16.7 \%$ of men) compared with that of the German studies. The higher incidence might be explained by the wider definition of forms of sexual harassment used in the German studies, ranging from degrading speech to sexual assault. Since our survey did not clearly define what could be classed as sexual harassment, milder forms (eg, verbal misconduct) might have been underreported by participants. Considering the disparity to the findings in Germany, further studies are urgently needed to assess the true extent of sexual harassment in the Swiss context.

When asked about the problems they faced, female participants reported problems in career progression, in the enforcement of maternity laws, as well as discrimination in hiring more frequently. This could explain at least in part the scarcity of women in senior positions in our study demographics. In the 'open-ended question' section of the survey, a few women used the metaphor of the 'glass ceiling' to describe the invisible barrier hindering women from accessing high responsibility positions despite having skills similar to their male peers. ${ }^{21}$ The 'sticky floor', in turn, is an analogous hindrance encountered at an earlier career stage. The needs more frequently expressed by female respondents (ie, support, mentoring, sponsorship in professional development, networking, knowledge and respect of their rights) also reflect the problems reported.

It is noteworthy that a majority of both female and male participants expressed the need to promote equality and inclusion in the medical field as well as their support for initiatives that contribute to these goals. The feminisation of the medical profession in Switzerland, with a $50 \%$ increase in female physicians in the last 10 years, has clearly not been sufficient to stop gender discrimination, even if the importance of diversified teams in terms of gender and the equivalent-to-superior competence of women physicians has been demonstrated. ${ }^{1422-24} \mathrm{~A}$ recent publication of the New England Journal of Medicine suggested that reframing gender bias and harassment as ethical issues in academics could help passive bystanders become active upstanders that have a professional and ethical duty to speak up and intervene when such acts occur. $^{25}$

\section{LIMITATIONS}

Due to the use of distribution via social media, the response rate could not be precisely estimated and the generalisability of the results should be considered with caution. The number of answers (1071) obtained is, nevertheless, important and we have a large panel of healthcare professionals and medical students who participated. A second limitation is the potential selection bias since the respondents might be those who were sensitive to the theme beforehand. This survey did not address other discrimination factors such as ethnicity, sexual orientation or religion. Nor did it assess who the perpetrators of gender discrimination or of sexual harassment were. A recent German study showed that the more severe forms of sexual harassment like forced physical contact were carried out by patients while sexual assault came mainly from staff and supervisors. ${ }^{20}$ Understanding this factor is essential to develop effective measures targeted at different groups of perpetrators.

\section{CONCLUSION}

Gender discrimination in medicine in French-speaking Switzerland affects one-third of women, in particular, those working in hospital settings and senior positions. Women report difficulties in career development, discrimination in hiring and working conditions and a non-respect of maternity laws more frequently. On the other hand, women and men reported having witnessed acts of sexism and sexual harassment at similar rates, demonstrating an awareness of the issue by both genders. Nearly $50 \%$ of men and two-thirds of women would support initiatives aimed at reducing gender discrimination and sexual harassment.

The findings of this survey prompt action on gender equality tailored to the medical field and serve as a foundation for further, more robust and detailed studies that should include an intersectional approach. Female and male medical doctors together should collect and assess data on gender discrimination and sexual harassment in a bottom-up manner and develop targeted interventions that reverberate at the structural and systemic levels. Finally, and most importantly, a change in medical culture that establishes an environment of zero tolerance against discriminatory behaviours and sexual harassment at all hierarchy levels is paramount.

\section{Author affiliations}

${ }^{1}$ Department of Medicine, HUG, Geneva, Switzerland 
${ }^{2}$ Departement of Primary Health Care, HUG, Geneva, Switzerland

${ }^{3}$ Departement of Clinical Epidemiology, HUG, Geneva, Switzerland

${ }^{4}$ Department of APSI, HUG, Geneva, Switzerland

${ }^{5}$ Faculty of Medicine, University of Geneva, Geneva, Switzerland

${ }^{6}$ Department of Rehabilitation and Geriatrics, HUG, Geneva, Switzerland

${ }^{7}$ Department of Obstetrics and Gynecology, HUG, Geneva, Switzerland

${ }^{8}$ Department of Maternity, Adolescent and Child Health, HUG, Geneva, Switzerland

${ }^{9}$ Departement of Cardiology, HUG, Geneva, Switzerland

${ }^{10}$ Department of General Internal Medicine, Delta Practice Network, Geneva,

Switzerland

${ }^{11}$ Department of Child Psychiatry, HUG, Geneva, Switzerland

${ }^{12}$ Departement of Neurology, Hôpital Lariboisière, Paris, France

${ }^{13}$ Deprtment of Emergency Care, Hirslanden Clinique La Colline, Geneva,

Switzerland

\section{Twitter Matteo Coen @matteocoen}

Acknowledgements We thank all the members of the association, MedFem, for their support and useful discussions.

Contributors IN analysed and interpreted the data and was a major contributor in writing the manuscript. JS made substantial contributions to the design of the work and was a major contributor in writing the manuscript. AG-A made substantia contribution in analysing the data and critically reviewing the manuscript. BR and $J A$ was a major contributor in the conception of the study and substantively revised the manuscript. JLB, AR, JA, CS, ET, CG, JH and GFP made substantial contributions to the conception and design of the study, the acquisition of the data and critically reviewed the manuscript. MC made substantial contribution in the conception of the work, the interpretation of the data and the revision of the manuscript. EN is the guarantor of this study and made substantial contribution to the conception and design and critically reviewed the manuscript. All authors have approved the submitted version and have agreed both to be personally accountable for their own contributions and to ensure that questions related to the accuracy or integrity of any part of the work, even ones in which they were not personally involved, are appropriately investigated, resolved and the resolution documented in the literature.

Funding The authors have not declared a specific grant for this research from any funding agency in the public, commercial or not-for-profit sectors.

Competing interests None declared.

Patient consent for publication Not applicable.

Provenance and peer review Not commissioned; externally peer reviewed.

Data availability statement Data are available upon reasonable request from the corresponding author, Iris Najjar, iris.najjar@gmail.com.

Supplemental material This content has been supplied by the author(s). It has not been vetted by BMJ Publishing Group Limited (BMJ) and may not have been peer-reviewed. Any opinions or recommendations discussed are solely those of the author(s) and are not endorsed by BMJ. BMJ disclaims all liability and responsibility arising from any reliance placed on the content. Where the content includes any translated material, BMJ does not warrant the accuracy and reliability of the translations (including but not limited to local regulations, clinical guidelines, terminology, drug names and drug dosages), and is not responsible for any error and/or omissions arising from translation and adaptation or otherwise.

Open access This is an open access article distributed in accordance with the Creative Commons Attribution Non Commercial (CC BY-NC 4.0) license, which permits others to distribute, remix, adapt, build upon this work non-commercially, and license their derivative works on different terms, provided the original work is properly cited, appropriate credit is given, any changes made indicated, and the use is non-commercial. See: http://creativecommons.org/licenses/by-nc/4.0/.

\section{ORCID iDs}

Iris Najjar http://orcid.org/0000-0003-3156-002X

Angele Gayet-Ageron http://orcid.org/0000-0002-6164-9693

Elena Tessitore http://orcid.org/0000-0003-1680-0152

Matteo Coen http://orcid.org/0000-0002-6156-1691

\section{REFERENCES}

1 International Labour Organization. Gender diversity journey: Company good practices. ILO, 2017. Available: http://www.ilo.org/ actemp/publications/WCMS_578768 [Accessed 25 June 2021].
2 Leading Women in Medicine Launch "Time's Up Healthcare". Available: https://www.medscape.com/viewarticle/909777\#vp_1 [Accessed 11 July 2020].

3 World Health Organization. Definition of sexual harassement. WHO, 2001. Available: http://www.un.org/womenwatch/osagi/pdf/who.pdf [Accessed 13 June 2021].

4 Jagsi R, Griffith KA, Jones R, et al. Sexual harassment and discrimination experiences of academic medical faculty. JAMA 2016;315:2120-1.

5 Larsson C, Hensing G, Allebeck P. Sexual and gender-related harassment in medical education and research training: results from a Swedish survey. Med Educ 2003;37:39-50.

6 Fnais $\mathrm{N}$, Soobiah $\mathrm{C}$, Chen $\mathrm{MH}$, et al. Harassment and discrimination in medical training: a systematic review and meta-analysis. Acad Med 2014;89:817-27.

7 Dzau VJ, Johnson PA. Ending sexual harassment in academic medicine. N Engl J Med 2018;379:1589-91.

8 National academies of sciences, engineering, and medicine; policy and global Affairs; Committee on women in science, engineering, and medicine; Committee on the impacts of sexual harassment in academia. sexual harassment of women: climate, culture, and consequences in academic sciences, engineering, and medicine. National academies press (US), 2018. Available: https://www.nap. edu/catalog/24994

9 World Health Organization. Delivered by Women, Led by Men: A Gender and Equity Analysis of the Global Health and Social Workforce. WHO, 2019. Available: http://www.who.int/hrh/resources/ health-observer24/en/ [Accessed 19 Dec 2020].

10 Governement United Kingdom. New data on gender pay gap in medicine. GOV.UK. Available: https://www.gov.uk/government/news/ new-data-on-gender-pay-gap-in-medicine [Accessed 10 Jul 2020].

11 Yong CM, Abnousi F, Rzeszut AK, et al. Sex differences in the pursuit of interventional cardiology as a subspecialty among cardiovascular Fellows-in-Training. JACC Cardiovasc Interv 2019;12:219-28.

12 Rampersad PP, Capdeville M. Who decided cardiology was a man's job? the future of cardiovascular medicine and why women are key. J Cardiothorac Vasc Anesth 2020;34:575-81.

13 Berlin G, Darino L, Greenfield M. Women in the healthcare industry. Mc Kinsey and Company, 2019. Available: https://www.mckinsey. com/industries/healthcare-systems-and-services/our-insights/ women-in-the-healthcare-industry\# [Accessed 19 Dec 2020]

14 Hostettler S, Kraft E. Statistique médicale 2019 de la FMH: Forte dépendance de l'étranger. Bull des Médecins Suisses 2020;101:450-5.

15 Association MedFem. Available: https://www.medfem.org/ [Accessed 11 Jul 2020]

16 SurveyMonkey - Free online survey software and questionnaire tool. Available: https://www.surveymonkey.com/

17 Casillas A, Paroz S, Green AR, et al. Cultural competency of health-care providers in a Swiss university hospital: self-assessed cross-cultural skillfulness in a cross-sectional study. BMC Med Educ 2014;14:19.

18 Lu DW, Lall MD, Mitzman J, et al. \#MeToo in EM: A Multicenter Survey of Academic Emergency Medicine Faculty on Their Experiences with Gender Discrimination and Sexual Harassment. West J Emerg Med 2020;21:252-60.

19 Jenner S, Djermester P, Prügl J, et al. Prevalence of sexual harassment in academic medicine. JAMA Intern Med 2019;179:108-11.

20 Schoenefeld E, Marschall B, Paul B, et al. Medical education too: sexual harassment within the educational context of medicine insights of undergraduates. BMC Med Educ 2021;21:1-6.

21 Hingle S, Barrett E. Gender differences in resident assessment: the glass ceiling and sticky floor for women in medicine begin early. JAMA Netw Open 2020;3:e2010985.

22 Tsugawa Y, Jena AB, Figueroa JF, et al. Comparison of hospital mortality and readmission rates for Medicare patients treated by male vs female physicians. JAMA Intern Med 2017;177:206-13.

23 Greenwood BN, Carnahan S, Huang L. Patient-Physician gender concordance and increased mortality among female heart attack patients. Proc Natl Acad Sci U S A 2018;115:8569-74.

24 Wang TY, Grines C, Ortega R, et al. Women in interventional cardiology: update in percutaneous coronary intervention practice patterns and outcomes of female operators from the National cardiovascular data Registry ${ }^{\circledR}$. Catheter Cardiovasc Interv 2016;87:663-8.

25 Mello MM, Jagsi R. Standing Up against Gender Bias and Harassment - A Matter of Professional Ethics. N Engl J Med 2020;382:1385-7. 